\title{
Ver-Sus: \\ Relato de Vivências na Formação de Psicologia
}

Ver-Sus: Experiences' Report On Psychology Formation Ver-Sus: Relato De Vivencias En La Formación De Psicología

Flavio Martins de Souza Mendes, Karina de Andrade Fonseca, Julia Alves Brasil \& Maristela Dalbello-Araúujo

Universidade Federal do Espírito Santo 
Resumo: Este artigo discute a formação em Psicologia a partir de uma experiência de estágio interdisciplinar de vivência, o projeto VER-SUS (Vivência e Estágio na Realidade do Sistema Único de Saúde), realizado por estudantes da área da saúde junto ao movimento estudantil desses cursos. A partir dessa experiência, ocorrida em 2008, no estado do Espírito Santo (VER-SUS/ES 2008), problematizamos a formação do psicólogo, afirmando a importância de ampliar a associação entre o ensino tradicional e ações que remetam às vivências interdisciplinares. Estas mesmas se configuram como estratégias de ensino-aprendizagem fundamentais para a Psicologia e para a área da saúde como um todo. Por fim, ressaltamos a importância da constante revisão das práticas, da formação e do papel do psicólogo, para pensarmos sobre outras formas de aprendizagem e diálogo ao longo do ensino superior.

Palavras-chave: Estágios. Formação do psicólogo. Interdisciplinaridade. Sistema Único de Saúde. Ensino de Psicologia.

Abstract: This article discusses the formation in Psychology from an experience of interdisciplinary internship, the project VER-SUS (Internship and Experience on the Unified Health System's Reality) made by students in the health area with the students' movement of these courses. From this experience, which occurred in 2008, in the state of Espírito Santo (VER-SUS/ES 2008), we discuss the formation of the psychologist, stating the importance of expanding the association between traditional teaching and actions referring to interdisciplinary experiences. These experiences take shape as fundamental teaching-learning strategies to Psychology and health area as a whole. Finally, we emphasize the importance of the constant review of the practices, of the instruction and of the role of the psychologist in thinking of other ways of learning and dialogue through undergraduation.

Keywords: Internships. Instruction of the psychologist. Interdisciplinarity. Unified Health System. Psyhcology education.

Resumen: Este artículo discute la formación en Psicología a partir de una experiencia de prácticas interdisciplinarias de vivencia, el proyecto VER-SUS (Vivencia y prácticas en la Realidad del Sistema Único de Salud) realizado por estudiantes del área de la salud junto al Movimiento Estudiantil de estos cursos. A partir de esa experiencia, ocurrida en 2008, en el Estado de Espírito Santo (VER-SUS/ES 2008), problematizamos la formación del psicólogo, afirmando la importancia de ampliar la asociación entre la enseñanza tradicional y acciones que remitan a las vivencias interdisciplinarias. Estas mismas se configuran como estrategias de enseñanza-aprendizaje fundamentales para la Psicología y para el área de la salud como un todo. Por fin, resaltamos la importancia de la constante revisión de las prácticas, de la formación y del papel del psicólogo, para pensar otras formas de aprendizaje y diálogo a lo largo de la enseñanza superior.

Palabras clave: Pasantías. Formación del Psicólogo. Interdisciplinaridad. Sistema Único de Salud. Enseñanza de Psicología.

Agradecemos a todos nossos colegas, estudantes de diversos cursos da área da saúde, que participaram do VER-SUS, aos professores e todos os outros parceiros que contribuíram com a orientação e a execução do projeto, aos gestores, profissionais e usuários dos serviços nos quais realizamos a vivência de 2008.
Neste artigo, objetivamos apresentar o relato de uma experiência de estágio interdisciplinar de vivência, o VER-SUS, com o intuito de discutir a formação em Psicologia e as contribuições de experiências como essa para a formação e a atuação dos profissionais da área da saúde.

A regulamentação do curso de Psicologia no Brasil aconteceu em 1962 (Lisboa \& Barbosa, 2009), período em que as questões sociais eram pouco consideradas nas discussões devido ao regime político ditatorial em vigor, que marcou uma época que regulava qualquer expressão de cidadania por suprimir direitos sociais, civis e políticos. Entretanto, no início da década de 1980, o cenário político começou a mudar em função do enfraquecimento do regime militar e da ascensão do regime democrático, impulsionado pela manifestação popular organizada em movimentos sociais que reivindicavam a livre manifestação da cidadania mediante a garantia dos direitos antes suprimidos (Couto, 2004).

Essa mudança de perspectiva política afetou diretamente a formação e a atuação em Psicologia. Antes da redemocratização, o trabalho do psicólogo pautava-se, basicamente, no diagnóstico, na terapia, no aconselhamento ou no exame psicotécnico. No entanto, 
segundo Branco (1998), "o tratamento psicológico é dirigido, principalmente, à burguesia; nos consultórios particulares e às classes populares, resta o atendimento psiquiátrico, como corretivo para o que é considerado um comportamento 'anormal'" (p.30). Ao emergirem as necessidades sociais, foi expandido o campo de atuação dos psicólogos e, em consequência, a formação, que precisou ir além da clínica curativa, focada no indivíduo.

Devido às reflexões realizadas, Psicologia passou a ampliar sua forma de atuação, visando a intervir para atender as demandas das classes menos abastadas (Boarini \& Borges, 2009). Apesar dessas mudanças, a área clínica manteve seu destaque ao longo dos anos, sendo possível constatar que ela ainda é amplamente contemplada nos cursos de graduação em Psicologia no Brasil (Ferreira Neto \& Penna, 2006; Noronha, 2003).

Considerando as mudanças e a ampliação da presença da Psicologia no cenário brasileiro, este artigo ressalta a importância de os estudantes estarem atentos para suas concepções e práticas, que muitas vezes se estabelecem como um movimento de psicologização da vida, individualizando a realidade cotidiana (Nascimento, Manzini, \& Bocco, 2006). O artigo também se baseia na defesa da ideia de que os cursos de formação de psicólogos devem permitir que o estudante veja e conviva com as divergências próprias da área, estimulando a percepção da inexistência de verdades absolutas ou a predominância de um único saber ou forma do fazer psi (Bettoi \& Simão, 2002).

A formação em Psicologia para a área da saúde vem sofrendo grandes mudanças em função de discussões em torno do currículo mínimo dos cursos de graduação, das metodologias de ensino-aprendizagem e das experiências de estágio. Tem sido ressaltada a necessidade de se construírem novas formas de ensinar e aprender face às mudanças contemporâneas, que ocorrem devido ao aumento da produção de conhecimento, à perspectiva de colocar em xeque as ideias vigentes, à influência dos meios de comunicação na interação humana e à configuração de uma nova forma de estar no mundo, marca da sociedade de controle. Essas transformações evidenciam a necessidade de se repensar o homem e sua articulação com o conhecimento, articulação essa que se fundamenta nas relações interpessoais, na valorização do contexto e de novas perspectivas e na integração do que antes era visto como antagonismo: corpo e mente, teoria e prática, ensino e aprendizagem, razão e emoção, ciência e fé (Mitre et al., 2008).

Verificamos que essa discussão sobre a avaliação dos currículos acadêmicos, a formação básica e a interlocução da formação com novas práticas de ensino-aprendizagem tem sido uma preocupação constante da Academia: como (re)inventar a formação para a área da saúde de forma que seja possível, ainda na graduação, unir a teoria discutida em sala de aula e nos laboratórios com a vivência do cotidiano de trabalho?

Alguns autores têm empreendido discussões nesse sentido: Bousso, Merighi, Rolim, Riesco e Angelo (2000) e Carvalho, Pelloso, Valsecchi e Coimbra (1999) discutiram a importância dos estágios nos cursos de enfermagem e as expectativas dos estudantes mediante essas experiências; Campos e Forster (2008) pesquisaram a percepção e a avaliação dos estudantes de Medicina quanto à importância atribuída aos estágios focados no tema saúde da família; Canônico e Brêtas (2008) apresentaram e discutiram os significados do projeto Vivência e Estágio na Realidade do Sistema Único de Saúde (VER-SUS) na formação profissional para a área da saúde, e Trenche, Barzhagi e Pupo (2008) apresentaram reflexões sobre mudanças nos projetos pedagógicos dos cursos de formação 
em fonoaudiologia. Em comum, esses autores propõem que a formação seja ampliada, reforçando a importância de unir o que é apreendido em sala de aula às vivências no cotidiano do trabalho em saúde, enfatizando que é igualmente indispensável o respaldo dessas propostas nos projetos pedagógicos dos cursos de graduação.

Outros autores que têm pensado sobre a formação em saúde são Abrahão et al. (2011) e Clemente et al. (2008). Os primeiros discutem o trabalho de pesquisa no Programa de Educação para o Trabalho para a Saúde (PET-SAÚDE) em Niterói, tendo o projeto a proposta de consolidar um espaço de ensinoaprendizagem com maior participação dos envolvidos, articulando pesquisa e avaliação em saúde. Já Clemente et al. (2008) discutem a formação em Psicologia a partir do que é vivido na residência multiprofissional em São Paulo, com as residências integrando pressupostos e diretrizes do SUS a aspectos do trabalho nas Estratégias de Saúde da Família (ESF), além da articulação em equipe de profissionais de profissões diferentes.

Na área da Psicologia, tem sido necessário discutir a formação do psicólogo visto a grande inserção desse profissional em novos e diferentes campos de atuação, como o da saúde pública, ao mesmo tempo em que se observa a pouca atenção dispensada aos estágios de vivência durante a formação (Ceccim \& Bilibio, 2004). De maneira geral, na formação, tem-se direcionado o aprendizado para a valorização de conteúdos teóricos e técnicos, com menor preocupação em vivenciar a realidade concreta, que poderia ser contemplada caso fosse possível inserir experiências de vivência e estágio junto a profissionais e usuários nos serviços de saúde nas propostas curriculares dos cursos de graduação de Psicologia (Mendes, Côco, Brasil, Fonseca, \& Dalbello-Araujo, 2008b).
Dessa maneira, percebe-se que as mudanças ocorridas no contexto socioeconômico nos últimos anos, em se tratando daquilo que Mitre et al. (2008) apresentaram, forçaram e têm forçado a busca pela inovação das formas de ensino-aprendizagem. Esses fatos que constituem as transformações contemporâneas, pensando sobre o que Boarini e Borges (2009) observam, têm influenciado a Psicologia a buscar formas de atuação diferentes devido a sua inserção em espaços antes incomuns para psicólogos. Além disso, esse conjunto de ideias já é evidenciado na área da Psicologia, considerando as discussões de Bettoi e Simão (2002), que se posicionam no sentido de os cursos de formação em Psicologia, no que tange ao ensino superior, darem condições aos alunos de aprenderem a interagir com divergências, considerando que as verdades são relativas e formadas por saberes variados.

Uma das premissas básicas do ensino superior é sistematizar a integração entre formação, trabalho e desenvolvimento social, o que constitui um grande desafio. Conforme o relatório da Conferência Mundial sobre o Ensino Superior, formulado pela Organização das Nações Unidas para a Educação, Ciência e Cultura (UNESCO), em 1999, essas alterações seriam: modificar as competências e o perfil das competências exigidas nas profissões, possibilitar conhecimentos gerais em informática e em outras tecnologias de comunicação e informação e formar profissionais dotados de conhecimentos amplos em diversas áreas (Bardagi, Bizarro, Andrade, Audibert, \& Lassance, 2008). Vêemse, assim, alterações no sentido da formação de profissionais generalistas e articulados com as novas ferramentas da comunicação e informação, assim como com a realidade de sua inserção.

De certa maneira, os currículos acadêmicos não priorizam a integração entre formação, 
1 Para a escolha dos cursos da área da saúde, seguimos

a Resolução de no 287/98, do

Conselho Nacional de Saúde. Essa resolução contempla os cursos: Biologia, Biomedicina, Enfermagem,

Educação Física, Odontologia, Medicina, Medicina Veterinária, Fisioterapia,

Fonoaudiologia, Farmácia, Nutrição, Psicologia, Serviço

Social e Terapia Ocupacional, acrescidos de Administração de Sistemas e

Serviços de Saúde

e Administração Hospitalar.

2 Ressaltamos que, dos quatro autores deste artigo, três atuaram no projeto VER-SUS/ES tanto como estagiários, por serem, na época, estudantes da graduação de Psicologia, quanto como membros da comissão organizadora do mesmo. A quarta autora, no entanto, atuou como coordenadora do curso de formação e da vivência. trabalho e sociedade. A partir de 2004, contudo, foram instituídas novas diretrizes curriculares nacionais para os cursos de Psicologia em todo o país, o que veio trazer mudanças na perspectiva de formação na área, visando a torná-la mais generalista e promotora da ampliação de experiências práticas durante a graduação ao favorecer a formação multiprofissional à medida que diferentes saberes da Psicologia poderão ser conhecidos e vivenciados de diversas formas (Bardagi et al., 2008). Essa perspectiva vai ao encontro das propostas de mudança curricular, de ensino-aprendizagem e de outros aspectos na constituição de profissionais generalistas, já discutidos anteriormente, tornando importante avaliar e pensar sobre a importância de projetos como o VER-SUS, tanto na formação na área da saúde como um todo quanto na formação dos estudantes de Psicologia.

\section{O projeto VER-SUS: seus objetivos e sua história}

Projetos que visam complementar a formação através de estágios interdisciplinares de vivência não são recentes, tampouco exclusivos da área da saúde. A construção do VER-SUS foi influenciada por diversos projetos realizados anteriormente, como: estágios interdisciplinares de vivência em assentamentos rurais, organizados pela Federação dos Estudantes de Agronomia do Brasil (FEAB) no final da década de 1980, projetos de estágio de vivência realizados pela Direção Executiva Nacional dos Estudantes de Medicina (DENEM), nos anos 1990, e o projeto Escola de Verão, realizado com o apoio da Escola de Saúde Pública do Estado do Rio Grande do Sul (ESP/RS), em 2002 (Ceccim \& Bilibio, 2004).

O projeto VER-SUS surgiu no Rio Grande do Sul, em julho de 2002, e representou a ampliação da experiência de estágio e vivência na área da saúde, de forma interdisciplinar, agregando diferentes cursos. No ano seguinte, com o apoio do Ministério da Saúde junto ao movimento estudantil dos cursos da área da saúde (1), foi planejada a realização do projeto em vários estados brasileiros, fato esse que se concretizou em 2004 com a implantação do projeto VER-SUS/BRASIL. O Espírito Santo foi um dos estados contemplados pelo projeto, que ocorreu em duas edições: uma, em 2004, e outra, em 2008.

Desde suas propostas iniciais, o VER-SUS se apoiou na parceria entre Ministério da Saúde e movimento estudantil dos cursos da área da saúde, formando uma interação políticosocial entre grupos dessa área. Esse projeto tem como principais objetivos: permitir maior contato de estudantes com os princípios e realidades do SUS, valorizar o compromisso ético dos participantes com os pressupostos da reforma sanitária, possibilitar o entendimento do conceito ampliado de saúde, permitir práticas profissionais interdisciplinares e intersetoriais, instigar os estudantes a participarem de movimentos sociais, em especial do movimento estudantil, permitir que os estudantes possam refletir sobre seu papel como agentes transformadores da realidade, estimular debates entre trabalhadores, gestores e estudantes acerca da Educação Permanente e estimular discussões em torno da implementação de novas diretrizes curriculares para a saúde, de forma que se tenha um projeto político-pedagógico dos cursos de graduação da área da saúde que contemplem aspectos da realidade do SUS (Ministério da Saúde, 2004a, 2004b).

Ao se considerar os objetivos propostos para o VER-SUS, tendo por base de fundo as mudanças sociais e o que elas produziram na reflexão sobre a mudança do currículo mínimo, das formas de ensino-aprendizagem, dentre outros aspectos discutidos anteriormente, constata-se como essa proposta de vivência e 
estágio está extremamente articulada ao que se propõe atualmente como alternativa para avaliar e intervir na formação acadêmica.

Além das edições do VER-SUS mencionadas anteriormente, há, ainda, notícias de seu desenvolvimento em outros estados (Estudantes Aproveitam o VER-SUS, 2006; Projeto VER-SUS Integra, 2007; Projeto VERSUS, 2009; Saúde Inicia Estágio, 2010). As diversas formas de organização mantêm as propostas centrais de articulação entre estudantes de diferentes áreas e destes com profissionais, gestores e usuários do SUS, considerando o diálogo e a reflexão acerca do SUS e as possibilidades de interação e de mudança social.

Após as vivências realizadas, principalmente as ocorridas em 2002 (Rio Grande do Sul), 2004/2005 (nacional) e 2008 (Espírito Santo), foram publicados diversos materiais em áreas distintas, sob a forma de relatos de experiência, de apresentação de dados de pesquisas sobre a vivência e de reflexão teórica das articulações e da importância do VER-SUS na formação profissional. Nessas publicações, discutem-se a realização do projeto devido à articulação entre Ministério da Saúde e movimento estudantil, além da promoção do encontro entre estudantes, do intercâmbio entre esses profissionais, gestores e usuários, no sentido da mudança de posturas, olhares, concepções e práticas sobre o SUS (Mendes et al., 2008; Riquinho \& Capoane, 2002; Torres, Rodrigues, Boeri, \& Pelaez, 2003).

A importância do VER-SUS como proposta teórico-metodológica ou metodologia ativa de formação é evidenciada em todos os artigos citados, pois o projeto apresenta-se como possibilidade de ampliar a formação por favorecer a unidade do que foi apreendido em sala de aula com a experimentação do cotidiano de trabalho no SUS. Essa questão deve ser vista como um fator relacionado aos objetivos a serem atribuídos ao projeto desde a sua formulação, como estágio e vivência, tocando nos aspectos teórico-práticos e vivenciais da/na formação dos estudantes da área da saúde. Como o foco não passa apenas por um dos aspectos, mas pela interlocução constante entre os três (teoria, prática e vivência), juntamente à interação entre estudantes, profissionais, gestores e usuários, a proposta do VER-SUS se coloca em um patamar ímpar em se tratando de metodologia para uma formação ética, interdisciplinar e integrada com a realidade social, cultural e histórica.

Assim, parece viável considerar o VER-SUS como uma proposta de mudança curricular fundamental para a formação dos cursos da área da saúde. A possibilidade de articulação entre teoria, prática e vivência, aspectos esses relacionados quando são realizadas discussões a respeito do VER-SUS, se insere nas propostas de metodologias de ensino-aprendizagem que permitam a constituição de saberes diferenciados. Esse aspecto parece estar de acordo com a discussão de Bettoi e Simão (2002), quando se posicionam a respeito de que os cursos de formação devem se colocar como norte, no sentido da constituição de múltiplos saberes, sem verdades absolutas, assim como nas discussões de Mitre et al. (2008), que apontam os caminhos para os quais as mudanças atuais têm seguido, na valorização das relações interpessoais, do contexto e de novas perspectivas.

Dessa forma, o VER-SUS é realizado como estágio interdisciplinar no qual os estudantes entram em contato com o trabalho de outros profissionais. Esse formato é diferente do modo como estamos acostumados a conceber um estágio, como um período de aprendizado de determinada profissão, no qual o estudante se familiarizará com os procedimentos técnicos de sua área de atuação. 


\section{O VER-SUS/ES 2008: um pouco da nossa vivência}

O VER-SUS aconteceu no Espírito Santo em dois anos distintos, um em 2004, o VER-SUS/BRASIL, e um em 2008, o VERSUS/ES. A formatação do VER-SUS 2008 foi bastante diferente em relação ao de 2004, apesar dos objetivos comuns, tendo em vista que a proposta nos chegou em outras circunstâncias e que não havíamos participado da experiência de 2004. Para a concretização da edição de 2008, obtivemos financiamento da UNESCO, cuja verba foi repassada para o Ministério da Saúde com o objetivo de realizar esse projeto. Além disso, contamos com o apoio de instituições como a Universidade Federal do Espírito Santo (UFES), por meio do Programa de PósGraduação em Saúde Coletiva (PPGSC), dos Departamentos de Enfermagem (DEPEN) e de Psicologia (DPSI) e da Fundação Ceciliano Abel de Almeida (FCAA), que efetuou a administração da verba repassada pelo Ministério da Saúde.

Nessa edição, da qual participamos tanto como organizadores quanto como estagiários (2), optamos por iniciar o estágio com um curso de formação, que durou três meses (abril a junho de 2008) e teve carga horária de 40 horas, totalizando seis encontros de cerca de duas horas. O objetivo desse curso foi promover o debate entre alunos, professores e demais profissionais sobre o histórico do SUS, o movimento estudantil e a construção do VER-SUS, a origem e o desenvolvimento da proposta do VER-SUS em nível nacional e estadual, a troca de experiências entre ex-estagiários e participantes dos debates, a explanação sobre a rede de saúde da região onde seria a vivência, a discussão da temática do trabalho em equipe e a discussão sobre a intersetorialidade entre as áreas da saúde (SUS) e da assistência social (SUAS).
Sabíamos que a discussão proposta era rica e se diferenciava de uma discussão tradicional na área da saúde. No entanto, só percebemos a grandiosidade e a riqueza dessa construção no primeiro dia de curso, quando esperávamos em torno de 60 estudantes da área, de diferentes cursos e instituições da Grande Vitória, e fomos surpreendidos com a participação de 230 estudantes de cursos como Enfermagem, Psicologia, Medicina, Fonoaudiologia, Terapia Ocupacional, Biologia, Serviço Social, Fisioterapia, Odontologia e Direito, de diferentes instituições da região metropolitana. Esse fato pôs em evidência a importância dada a debates interdisciplinares por estudantes e profissionais de áreas distintas, que se propuseram a estar reunidos para discutir a construção e a efetivação do SUS.

Em cada encontro, foram apresentados e discutidos os conteúdos por professores da área da saúde que militam no SUS e que se engajaram na construção do Projeto VER-SUS em outros lugares do país, por ex-estagiários que participaram das edições anteriores e por gestores e trabalhadores da saúde e da assistência social. Durante a exposição, eram propostas questões para posterior debate entre os apresentadores das temáticas e os demais participantes envolvidos.

Ao longo de cada encontro do curso, nós, organizadores, enfrentamos alguns dilemas. Um deles foi a definição da quantidade de estudantes que iriam participar do estágio de vivência, a ser realizado em municípios do norte do estado durante o mês de julho. Havia limitações em relação à logística e ao financiamento desse momento do projeto; assim, como forma de seleção dos participantes durante o curso, sugerimos avaliações seriadas e exigimos frequência mínima de $75 \%$ ao longo dos seis encontros. As avaliações eram reflexões individuais sobre cada encontro a serem entregues no encontro seguinte para que fossem lidas, discutidas e avaliadas pelos organizadores. 
Embora essa ação tenha sido decisiva para conseguirmos realizar a seleção dos estagiários, nós nos questionávamos em função de incômodos relacionados a: como selecionar pessoas que estão na mesma condição que a nossa, de estudantes da graduação? Como avaliá-los? Nesse sentido, discutimos nossas impressões e os propósitos do Projeto VER-SUS ao final de cada encontro do curso. Por isso, fomos entendendo que cabia a nós, mais do que selecionar ou possibilitar que alguns alunos participassem da vivência, instigar cada estudante, em cada dia de encontro, a interessar-se pela proposta e a desejar levá-la adiante.

Mesmo com algumas desistências, permanecemos com um expressivo número de estudantes que continuaram participando dos encontros e atendendo aos critérios estabelecidos para a seleção. Em junho, analisamos todas as avaliações e a lista de frequência e entrevistamos cada um dos 39 participantes que haviam atendido aos critérios de seleção.

Para selecioná-los, utilizamos fichas de avaliação contendo itens avaliados individualmente pelos quatro organizadores: 1) exercício de reflexão (se o entrevistado fez os exercícios), 2) experiência e participação (se o entrevistado participou/participava de discussões e estágios e como tinha sido/ era sua participação), 3) movimento social (se o entrevistado participou/participava de movimentos sociais e como tinha sido/era sua participação), 4) participação nas palestras, 5) motivação para participar do estágio e 6) impressão dos organizadores. Cada item foi avaliado com um valor entre 0 e 10 , e, ao final, foram somados todos os itens das fichas de cada participante e avaliados os resultados para que a escolha fosse realizada. Dessa forma, a avaliação exigiu muitos debates internos entre os organizadores, no sentido de avaliar com fins associados aos objetivos propostos no projeto.
Foram selecionados 16 estudantes (14 do sexo feminino e 2 do sexo masculino) de cinco diferentes cursos e de diferentes instituições de ensino da Grande Vitória. A proporção de estudantes selecionados de cada curso foi decidida com base no total de presentes durante os seis dias da formação. Desse modo, dos 16 selecionados, contamos com 7 estudantes de Enfermagem, 1 de Fisioterapia, 6 de Medicina, 1 de Psicologia e 1 de Odontologia. A comissão organizadora foi composta por 4 integrantes, 2 do sexo feminino e 2 do sexo masculino, sendo 3 estudantes de Psicologia e 1 estudante de Enfermagem. Além dos 20 estagiários (visto que os componentes da organização também se encontravam em processo de estágio), houve a participação de 2 facilitadores, que eram profissionais da saúde que haviam participado do estágio em 2004, quando ainda eram estudantes do curso de Fisioterapia.

Antes de iniciarmos o estágio de vivência, realizamos dois dias de debates em Vitória/ ES, já com os estudantes selecionados e com os facilitadores, tendo como foco os movimentos sociais e suas intercessões com a área da saúde. Vale ressaltar que esse número de 22 pessoas na equipe do VERSUS/ES 2008 (16 estagiários selecionados, 4 organizadores e 2 facilitadores) foi decidido com base na verba que tínhamos disponível para viabilizar hospedagem, alimentação, transporte e material, além do fato de que um número maior de participantes talvez pudesse dificultar nossa entrada nos serviços de saúde, prejudicando tanto o seu funcionamento quanto a qualidade da vivência.

O estágio de vivência ocorreu nos municípios de Ibiraçú, Aracruz e Santa Tereza, localizados no norte do estado do Espírito Santo. Foram oito dias intensos de vivência em estabelecimentos ligados ao SUS em todos os seus níveis de atenção. Também foram 
oito dias intensos de convivência entre profissionais, estudantes, gestores de saúde e usuários dos serviços.

Todo o cronograma de visitas foi discutido entre os estudantes e representantes dos profissionais e dos gestores, uma vez que entendemos que o processo de estruturação dessa vivência deveria constituir uma construção coletiva e cotidiana entre as partes envolvidas. Formamos quatro grupos de cinco estagiários cada, que participavam de diferentes serviços diariamente. Os dois facilitadores alternavam-se entre os diferentes grupos, conforme a necessidade dos participantes. As vivências aconteceram tanto pela manhã quanto à tarde, com pausas para almoço e lanche de acordo com os horários de cada grupo, no próprio hotel em que os estudantes estavam hospedados. Nessas oportunidades, fazíamos anotações sobre nossas reflexões, observações e dúvidas, além de conversarmos com profissionais e usuários dos serviços e com os próprios estudantes. No período noturno, nós nos reuníamos para trocar informações e impressões sobre os serviços e para registrar, sob a forma de portfólios, a problematização de nossas experiências. Dessa forma, na discussão no período noturno, cada grupo pôde compartilhar sua experiência e suas elaborações com os demais grupos.

Nesse período, a vivência configurou-se como um espaço de troca de informações sobre as práticas e os conhecimentos elaborados na experiência do estágio, uma vez que os estudantes estiveram em contato com a realidade social, com o dia a dia do trabalho no SUS, com os profissionais e com os gestores e os usuários. Dessa maneira, pudemos construir conhecimentos e práticas que diziam respeito a questões que ultrapassam a formação específica de cada curso, chegando a um terreno interdisciplinar, ético e político.
Durante a vivência, conhecemos o cotidiano de serviços da área da saúde e de serviços de áreas afins a ela articuladas em rede. Os serviços dizem respeito às atenções primária, secundária e terciária da área da saúde, às educações regular e especial na área da educação, aos projetos em funcionamento na Secretaria de Ação Social, assim como a ações ligadas a entidades filantrópicas relacionadas à Igreja Católica e aos movimentos sociais Sem-Terra e Aldeias Indígenas.

Mediante as discussões empreendidas entre estudantes, gestores, usuários e profissionais, foram construídas algumas reflexões e, destas, preparamos propostas possíveis de serem debatidas e implementadas em todos os serviços visitados em se tratando do Sistema Único de Saúde (SUS) brasileiro.

\section{O que pensamos a partir dessa vivência?}

Consideramos que esse tipo de estágio deve ser realizado de forma contínua, buscando abarcar o maior número de estudantes e maior variedade de cursos da área da saúde, uma vez que ele constitui espaço de encontro entre diferentes visões e práticas desse campo. Essa ação possibilita que os estudantes se tornem comprometidos com a qualidade e a efetivação do SUS, garantindo uma assistência adequada aos usuários desse sistema e dos demais sistemas e serviços articulados em rede. Também entendemos que é importante que propostas como essa sejam adotadas também entre profissionais, ao longo de toda a carreira. Uma possibilidade é a Educação Permanente, que seria uma formação profissional e até mesmo uma construção pessoal de um trabalhador em seu campo de atuação. No entanto, é preciso pensar na formação do profissional ainda como estudante.

Assim, diante da realidade na qual se encontra a formação em Psicologia atualmente e da 
De acordo com Boarini e Borges (2009), a atuação da Psicologia vem se modificando pelas intervenções dos profissionais da área nas demandas sociais, ao passo que Ferreira Neto e Pereira (2006) e Noronha (2003) relatam que a formação clínica ainda é fortalecida na graduação. existência de propostas como o VER-SUS, vemos que esse projeto se configura como uma estratégia de ensino-aprendizagem fundamental para esse campo e para toda a área de saúde. Assim, estamos de acordo com Canônico e Brêtas (2008) quando afirmam que possibilidades de ampliar a formação com projetos como o VER-SUS constituem importantes ferramentas para mudarmos $O$ modo como o conhecimento é transmitido e debatido nas universidades. Questionar esse modo implica, em consequência, a mudança da atitude profissional, uma vez que a reelaboração do saber e das práticas sobre o SUS problematizam as relações de poder entre quem defende e luta pela efetivação do SUS e quem crê que o sistema possa ser gerenciado como mercadoria.

O VER-SUS se concretiza, portanto, como possibilidade de ampliação da formação profissional, especialmente em Psicologia, uma vez que possibilita a aproximação, ainda na graduação, dos estudantes com diversos serviços que atravessam a área da saúde e seus trabalhadores e usuários, fato esse evidenciado no relato da vivência do estágio. Sua criação provoca novas formas de proceder mediante a realidade de que ainda são poucos os espaços consolidados em que profissionais de diferentes áreas trocam experiências e impressões entre si, com os estudantes e com os usuários dos serviços em que atuam.

Isso demonstra que a integração entre profissionais e diferentes serviços ainda é uma realidade a ser construída, assim como o aprofundamento da reflexão sobre a sua interação com a Academia. Outro desafio que se coloca é pensarmos sobre como pode ser feita essa aproximação sem esquecermos o direito dos usuários à participação e ao controle social na saúde, considerando a importância dessa participação na constituição e na execução do Sistema Único de Saúde. Assim, o VER-
SUS se propõe a integrar todos esses saberes, relativos aos estudantes, aos profissionais, aos gestores e aos usuários envolvidos na área da saúde, possibilitando que esses atores se relacionem de maneira a articular diferentes níveis de diálogos e interações. Junto a isso, possibilita que os estudantes se aproximem de forma mais intensa da realidade de trabalho no SUS, ainda estando na graduação (Mendes et al., 2008a).

Entendemos que projetos como esse, que objetivam problematizar a formação profissional por insistirem em intensificar a relação teoria-prática ainda na graduação dos cursos da área da saúde, são instrumentos fundamentais para que o estudante em formação conheça a realidade de trabalho do seu campo profissional em diferentes espaços, sejam eles públicos ou privados. Essa realidade coloca-o em contato tanto com técnicas próprias de seu campo de atuação (no caso da Psicologia, em especial, do aprimoramento da escuta e do acolhimento, por exemplo) quanto com as diferentes formas de relacionamentos que se estabelecem no ambiente de trabalho: com os colegas de profissão, com os de outras profissões, com gestores, com usuários.

No que diz respeito à formação em Psicologia, o VER-SUS possibilita uma forma de vivência e estágio que coloca em questão outros espaços de atuação e de interação com os demais profissionais da área da saúde. De acordo com Boarini e Borges (2009), a atuação da Psicologia vem se modificando pelas intervenções dos profissionais da área nas demandas sociais, ao passo que Ferreira Neto e Pereira (2006) e Noronha (2003) relatam que a formação clínica ainda é fortalecida na graduação. O VER-SUS nos parece uma proposta interessante para ser colocada na interface da Psicologia com outras áreas pelo fato de os cursos de Psicologia terem foco maior na área clínica. 
Em avaliação posterior ao momento do estágio, constatamos que o VER-SUS ofereceu também aos estudantes a riqueza da vivência de um cotidiano interdisciplinar, seja na formação, seja na atuação, ao possibilitar o contato dos estagiários com a própria realidade profissional, com a realidade profissional de trabalhadores de outras áreas da saúde e de outras áreas de conhecimento que se articulam com a saúde, de estimular o aprendizado para além dos conhecimentos de teorias ou de técnicas e de propiciar a vivência, com outros estudantes, dos desafios da formação profissional. O VER-SUS possibilitou aos participantes um componente fundamental para uma formação comprometida com a articulação entre os aspectos técnicos, éticos e de relacionamento interpessoal: a vivência do cotidiano.

Destaca-se a importância dessa forma de estágio para a formação em saúde naquilo que Ceccim e Bilibio (2004) discutem sobre a articulação da área da saúde com os segmentos estudantis, abrindo espaço para estratégias que inovem a formação, considerando que os movimentos sociais como um todo têm algo a contribuir na formação dos profissionais que irão se inserir na dinâmica social. Juntamente a isso, considerando os apontamentos de Schaedler (2004), valorizar a proposta (nesse caso, o VER-SUS) no sentido de possibilitar novas práticas pedagógicas que sejam disruptoras, que instituam novos modelos na educação.

Entre nós, foi unânime a constatação de que participar desse projeto deu mais sentido à formação. Podemos falar com propriedade sobre os impactos positivos que o projeto promoveu no grupo participante em 2008. Várias reuniões posteriores à vivência de 2008 foram organizadas, sempre com a presença de novos membros também, na busca da continuidade do projeto e de que fosse levada a outros estudantes a possibilidade de vivenciar e problematizar o SUS ainda na graduação.

Como aspecto negativo, no entanto, podemos dizer que não houve novas parcerias que pudessem apoiar tanto financeiramente quanto pedagogicamente o projeto, o que fez com que o mesmo se desarticulasse no estado do Espírito Santo. Além disso, não obtivemos registros que indicassem que cursos da área da saúde reestruturaram seus currículos objetivando incluir momentos de vivência do cotidiano profissional com base na proposta do VER-SUS.

Nesse sentido, entendemos que a força do projeto se encontra em seu poder de articulação do movimento estudantil com outros atores (como instituições de ensino superior, instituições governamentais ligadas à gestão e à formação de recursos humanos para a saúde pública, outros movimentos sociais, usuários dos serviços), seja no nível de apoio financeiro, burocrático, seja no de construção, no de execução ou no de avaliação. É importante que projetos como o que discutimos aqui sejam implementados de forma continuada, uma vez que possibilitam ao estudante uma formação integral ao apresentar o aprendizado em sala de aula atrelado ao cotidiano de trabalho.

\section{Reflexões e considerações finais}

Discussões acerca da formação em Psicologia, a fim de refletirmos sobre o que estamos fazendo de nossa profissão, nossa formação e nossa prática, são fundamentais para ampliarmos as possibilidades de entendimento da proposta política da atuação do psicólogo. Entendemos, concordando com Freire (1983), que o homem é inacabado e tem consciência disso, que não há sujeito pronto, que somos todos inconclusos. Assim também a Psicologia 
e nossa formação são inconclusas e se refazem constantemente na práxis. Portanto, é importante estarmos atentos a isso quando falamos de formação profissional, seja em Psicologia, seja em qualquer outra área, pois estamos falando, ao mesmo tempo, de Psicologia em formação, em constante construção, transformação, invenção.

Aos estudantes em formação e aos psicólogos, faz-se o convite: atentar para a função social do psicólogo, para a atuação pautada no compromisso social, problematizando a sua intervenção com foco na ideia de que o mais importante não é com quem se está comprometendo, mas a forma como se dá esse compromisso (Yamamoto, 2007). Além disso, é necessário que o psicólogo valorize aspectos da formação tradicional em Psicologia, que deve ser sempre reconstruída, assim como, concomitantemente, se abra à possibilidade de intervenção interdisciplinar junto a outros profissionais, a outros sujeitos e em novos locais de trabalho (Silva \& Merlo, 2007).

Dessa forma, é necessário que haja novas práticas pedagógicas, novas possibilidades para a educação, que se tenha "uma prática disruptora de modelos previamente instituídos" (Schaedler, 2004, p.67). Nesse sentido, demonstramos que experiências como a do VER-SUS podem trazer grandes contribuições para a formação técnica, política e ética dos estudantes envolvidos (Canônico \& Brêtas, 2008).

O VER-SUS permite que, durante o processo de formação, os estudantes tenham contato com um cotidiano de trabalho que engloba diversas áreas de conhecimento, possibilitando, desse modo, uma formação mais qualificada e consciente de seus direitos e deveres como profissionais. Vivências como as propostas pelo PET-SAÚDE, cujo norteador é a articulação ensino-serviço-comunidade, e pelas residências multiprofissionais também seguem percursos próximos aos propostos pelo VER-SUS, por isso, a importância de que experiências como essas, de estágio interdisciplinar, de vivência na realidade na qual se irá atuar, de formação em equipe, continuem sendo realizadas e ampliadas para os diversos campos de atuação da Psicologia e também de outras áreas de conhecimento. 


\section{Flavio Martins de Souza Mendes}

Mestrando no Programa de Pós-Graduação em Psicologia da UFES, Espírito Santo - ES - Brasil.

E-mail: flaviomsmendes@yahoo.com.br

Karina de Andrade Fonseca

Mestranda no Programa de Pós-Graduação em Psicologia da UFES, Espírito Santo - ES - Brasil

E-mail: kandradefonseca@yahoo.com.br

Julia Alves Brasil

Mestranda no Programa de Pós-Graduação em Psicologia da UFES, Espírito Santo - ES - Brasil E-mail: juliaalvesbrasil@gmail.com

Maristela Dalbello-Araújo

Doutorado em Psicologia pela Universidade Federal do Espírito Santo, Brasil(2005)

Professor Associado da Universidade Federal do Espírito Santo, Espírito Santo - ES - Brasil.

E-mail: dalbello.araujo@gmail.com

Endereço para envio de correspondência:

Rua Doutor João Batista Miranda Amaral, no 306, Condomínio Parque das Castanheiras, bloco B, Ed. Verdes Mares, ap. 404, Bairro Jardim Camburi. Vitória - ES - Brasil. CEP: 29090-380

Recebido 2/6/2011, 1a Reformulação 6/10/2011, Aprovado 15/10/2011. 


\section{Referências}

Abrahão, A. L., et al. (2011). A pesquisa como dispositivo para o exercício no PET-Saúde UFF/FMS Niterói. Rev. Bras. Educ. Med., 35(3), 435-440.

Bardagi, M. P., Bizarro, L., Andrade, A. M. J., Audibert, A., \& Lassance, M. C. P. (2008). Avaliação da formação e trajetória profissional na perspectiva de egressos de um curso de Psicologia. Psicologia: Ciência e Profissão, 28(2), 304-315.

Bettoi, W., \& Simão, L. M. (2002). Entrevistas com profissionais como atividade de ensino-aprendizagem desejável na formação do psicólogo. Psicologia: Reflexão e Crítica, 15(3), 613-624.

Boarini, M. L., \& Borges, R. F. (2009). O psicólogo na atenção básica à saúde. Psicologia: Ciência e Profissão, 29(3), 602-613.

Bousso, R. S., Merighi, M. A. B., Rolim, M. A., Riesco, M. L. G., \& Angelo, M. (2000). Estágio curricular em enfermagem: transição de identidades. Revista Escola de Enfermagem da USP, 34(2), 218-225.

Branco, M. T. C. (1998). Que profissional queremos formar? Psicologia: Ciência e Profissão, 18(3), 28-35.

Breunig, M., Fogaça, J. M., Torres, O. M., \& Fernandes, D. (2003). Projeto VER-SUS/RS: articulação entre movimento estudantil e gestão da formação de recursos humanos para o SUS. In 5 Congresso Nacional da Rede Unida. Resumo recuperado em 15 agosto, de http://www.ccs.uem.br/ especializacaoSF/RedeUnida/html/pg413.html.

Campos, M. A. F., \& Forster, A. C. (2008). Percepção e avaliação dos alunos do curso de medicina de uma escola médica pública sobre a importância do estágio em saúde da família na sua formação. Revista Brasileira de Educação Médica, 32(1), 83-89.

Canônico, R. P., \& Brêtas, A. C. P. (2008). Significado do programa vivência e estágios na realidade do Sistema Único de Saúde para formação profissional na área da saúde. ACTA Paulista de Enfermagem, 21(2), 256-61.

Carvalho, M. D. B., Pelloso, S. M., Valsecchi, E. A. S. S., \& Coimbra, J. A. H. (1999). Expectativas dos alunos de enfermagem frente ao primeiro estágio em hospital. Revista da Escola de Enfermagem da USP, 33(2), 200-206.

Ceccim, R. B., \& Bilibio, L. F. S. (2004). Articulação com o segmento estudantil da área de saúde: uma estratégia de inovação na formação de recursos humanos para o SUS. In Ministério da Saúde (Org.), VER-SUS/BRASIL: Cadernos de Textos (pp. 4-19). Brasília, DF: Gráfica Universitária.

Clemente, A., et al. (2008). Residência multiprofissional em saúde da família e a formação de psicólogos para a atuação na atenção básica. Saúde Soc., 17(1), 176-184.

Couto, B. R. (2004). O direito social e a assistência social na sociedade brasileira: uma equação possível? São Paulo: Cortez Estudantes aproveitam o VERSUS (Vivência no SUS). (2006). Recuperado em 15 agosto, 2010, de http://www.fmj.br/ noticias-visualizar.asp? NoticialD $=57$.

Ferreira Neto, J. L., \& Penna, L. M. D. (2006). Ética, clínica e diretrizes: a formação do psicólogo em tempos de avaliação de cursos. Psicologia em Estudo, 11(2), 381-390.

Freire, P. (1983). Pedagogia do oprimido. Rio de Janeiro: Paz e Terra.

Lisboa, F. S., \& Barbosa, A. J. G. (2009). Formação em psicologia no Brasil: um perfil dos cursos de graduação. Psicologia: Ciência e Profissão, 29(4), 718-737.

Mendes, F. M. S., Côco, G. C., Brasil, J. A., Fonseca, K. A \& Dalbello-Araújo, M. (2008a). VER-SUS: a importância de estágios de vivência para a formação profissional em psicologia. In 7 Congreso Internacional de Derechos Humanos y Salud Mental (s.p.). Buenos Aires, Argentina.

Mendes, F. M. S., Côco, G. C., Brasil, J. A., Fonseca, K. A., \& Dalbello-Araujo, M. (2008b). Relatos de uma experiência de estágio interdisciplinar: possíveis caminhos para a psicologia.
In Anais do III Congresso Capixaba de Formação e Atuação do Psicólogo: Éticas e Cidadanias (p.100). Vitória, ES: Programa de Educação Tutorial em Psicologia da Universidade Federal do Espírito Santo.

Ministério da Saúde. Secretaria de Gestão do Trabalho e da Educação na Saúde. Departamento de Gestão da Educação na Saúde. (2004a). VER-SUS Brasil: Caderno de Textos. Brasília, DF: Autor.

Ministério da Saúde. Secretaria de Gestão do Trabalho e da Educação na Saúde. Departamento de Gestão da Educação na Saúde. (2004b). Política de educação e desenvolvimento para o SUS: caminhos para a Educação Permanente em saúde: pólos de Educação Permanente em saúde. Brasília, DF: Autor.

Mitre, S. M., et al. (2008). Metodologias ativas de ensinoaprendizagem na formação profissional em saúde: debates atuais. Ciência \& Saúde Coletiva, 13(2), 2133-2144.

Nascimento, M. L., Manzini, J. M., \& Bocco, F. (2006). Reinventando as práticas psi. Psicologia \& Sociedade, 18(1), 15-20.

Noronha, A. P. P. (2003). Docentes de psicologia: formação profissional. Estudos de Psicologia, 8(1), 169-173.

Projeto VER-SUS. (2009). Recuperado em 15 agosto,2010, de http://www.opiniaodeipiau.com.br/2009/07/28/projeto-versus/.

Projeto VER-SUS integra acadêmicos à realidade do SUS. (2007). Recuperado em 15 agosto, 2010, de http://www.ufrr.br/ noticias/extensao/projeto-versus-integra-academicos-arealidade-do-sus.

Riquinho, D. L., \& Capoane, D. S. (2002). VER-SUS/RS: um olhar de estudantes universitárias sobre o Sistema Único de Saúde no Rio Grande do Sul. Boletim da Saúde, 16(1), 147-152.

Saúde inicia estágio de vivência no SUS Campinas. (2010). Recuperado em 15 agosto, 2010, de http://www.jusbrasil. com.br/politica/4469896/saude-inicia-estagio-de-vivenciano-sus-campinas.

Schaedler, L. I. (2004). Sistema Único de Saúde como rede em prática pedagógica. In Ministério da Saúde (Org.). VER-SUS/ BRASIL: Cadernos de Textos (pp. 85-91). Brasília, DF: Gráfica Universitária.

Silva, P. C., \& Merlo, A. R. C. (2007). Prazer e sofrimento de psicólogos no trabalho em empresas privadas. Psicologia: Ciência e Profissão, 27(1), 132-147.

Tomimatsu, T. C. O. (2006). VER-SUS/Brasil e a formação dos estudantes de serviço social. Trabalho de conclusão de curso, Instituto de Ciências Humanas, Universidade de Brasília, Brasília, DF.

Torres, O. M., Rodrigues, H. C. P, Boeri, V. A., \& Pelaez, P. L. (2003). Vivência-estágio na realidade do Sistema Único de Saúde no Rio Grande do Sul: um relato de experiência. In 5 Congresso Nacional da Rede Unida. Resumo recuperado em 15 agosto, 2010, de http://www.ccs.uem.br/especializacaoSF/ RedeUnida/html/pg499.html.

Trenche, M. C. B., Barzaghi, L., \& Pupo, A. C. (2008). Mudança curricular: construção de um novo projeto pedagógico de formação na área da fonoaudiologia. Interface - Comunicação, Saúde, Educação, 12(27) 697-711.

Yamamoto, O. H. (2007). Políticas sociais, "terceiro setor" e "compromisso social": perspectivas e limites do trabalho do psicólogo. Psicologia \& Sociedade, 19(1), 30-37. 